\title{
ON AN IMPROVED CONSTRUCTION OF AXLEBOXES AND COUPLING RODS FOR LOCOMOTIVE ENGINES.
}

This construction of axlebox has for its object the introduction of an elastic cushion or spring of vulcanised india-rubber between the axleboxes and framing of locomotive engines, for the purpose of allowing the wheels to accommodate themselves to curved portions of the railway, and thus to diminish the wear on the flanges of the wheels and on the faces of the axleboxes. The india-rubber spring is placed in recesses formed in the jaws of the horn plates upon each side of the axlebox, and a metal plate with a smooth casehardened surface is interposed, upon which the axlebox slides vertically with the ineqnalities of the road. The force of the spring action of the indiarubber is made sufficient to keep the axles of the wheels at right angles to the straight portions of the railway, but to yield to the friction of the rails upon the wheels in curved portions, and by this means to allow the axles to assume such a position as will place the wheels at a tangent to the curve. The elasticity of the indiarubber serves also to keep the axleboxes at all times in close contact with the faces of the horn blocks, so as to secure a good fit and obviate the necessity for that constant lining which they ordinarily require in consequence of the wearing away of the working faces.

The construction of the axleboxes is shown in Figs. 1 to 5, Plate 41, which represent the india-rubber applied to the trailing or leading and to the driving wheels of a locomotive engine. Fig. 1 is a half section and Fig. 2 a plan of an axlebox of the leading or trailing wheels; and Fig. 3 a side view, showing the position of the indiarubber washers.

$A$ is the axlebox itself, $B$ the jaws of the horn plate between which the axlebox slides; these jaws are recessed to contain the indiarubber springs $\mathrm{C}$, and the face plates $\mathrm{D}$ which cover them. These plates are casehardened, and hence form an exceedingly smooth surface for the axleboxes to slide on ; they rest upon the india-rubber 
springs $C$, and a space of $\frac{1}{8}$ inch is left between them and the jaws $B$ of the horn blocks, allowing the axlebox to play $\frac{1}{8}$ inch either way in the direction of the length of the engine, whenever the strain upon the wheels is sufficient to compress the india-rubber to that extent. That the leading and trailing wheels may have still further flexibility of adjustment, a small play is permitted to the axlebox laterally in the direction of the axle by making the recess in the axlebox, in which the plate D slides, wider than the plate itself by $\frac{1}{2}$ inch. But to keep the axleboxes in position in straight purtions of the road, the plates $D$ are made wedge-shaped in plan, so that the elasticity of the indiarubber restores the axleboxes to their central position whenever the pressure on the Alariges of the whoels is relicved. The inclination of the wedge is made such that $\frac{1}{4}$ inch movement of the axlebox laterally in either direction compresses the india-rubber $\frac{1}{8}$ inch.

The india-rnbber is expluyed in the form of rings or washers $\frac{13}{16}$ inch thick; and it is found convonient, in order to maintain an accurate fit between the working surfaces of the axleboxes, that these washers when in position should be compressed $\frac{s}{16}$ inch, which is equivalent to a pressure of about 1 ton on each side of the axlebox, tending to maintain the contact of the working surfaces. With this pressure the axleboxes slide more freely on the caschardened surface of the plates $D$ than in the usual construction; whilst the motion which permits the whels to accommodate themselves to the curvature of the roal does not in the least increase the oscillation of the engine, and prevents the excessive wear of the shoulders of the journals and of the flanges of the wheels, which are such fertile causes of unsteadiness in ordinary engines. A spocimen is shown of the vulcanised india-rubber taken from the axlebox of the leading wheel of an engine, in which it had run 17,000 miles; it is still uninjured, and retains its elasticity as perfect as when first introduced.

In the case of the driving wheels of the engine, it is not adrisable to allow so much play to the axleboxes; and hence, whilst the admirable fit between the working surfaces obtained by the above arrangement renders its employment advantageous, it is modified in this case as represented in Figs. 4 and 5 , which show a half section and plan of an axlebox for the driving wheels of a locomotive. The india-rubber $E$ 
consists of a flat band $12 \frac{1}{2}$ by $2 \frac{1}{2}$ inches and $\frac{3}{8}$ inch thick. It is covered by a wrought iron plate $F$, casehardened as before, but not wedge-shaped, since in this case all lateral play is to be avoided. A longitudinal play of $\frac{1}{32}$ inch only is allowed on each side between the casehardened plate $F$ and the horn blocks $G$, to permit the action of the india-rubber spring, which is compressed in this case so as to exert an initial pressure of about 15 tons on each side of the axlebox to resist the action of the force driving the engine. Notwithstanding this large pressure on the working faces of the box it is found in practice to fall readily with the weight of the wheel itself. In the case of the driving wheel the advantage derived by this construction does not consist in the adjustment given to the wheels, but in the perfect fit at all times maintained between the sliding surfaces, the elasticity of the india-rubber making up for the wear of the axlebox, and obriating the necessity for lining up after a short period of running. The india-rubber also forms an elastic cushion to receive the shocks of the machinery. A small strip of leather shown at $\mathrm{H}$, Fig. 4, prevents the oil from gaining admission to the indiarubber.

The perfect freedom of motion, the small wear of the axlebox in consequence of the casehardening of the slides, the ease with which the engine passes curves, and the diminished wear of the wheel flanges are important advantages, which have been derived in practice from this construction of axlebox.

In Figs. 6 and 7 is shown a similar application of an india-rubber spring I to the outside coupling rods of an engine. In this construction of rods the use of cotters for tightening the brasses is dispensed with by employing a set screw $\mathbf{K}$ at the end of the rod, secured by a lock-nut from risk of working loose. 
Mr. W. Falrbairn showed a specimen of the india-rubber lining from an axlebox that had run 17,000 miles in a locomotive engine; also a model of the axlebox fitted up with india-rubber, and a specimen of one of the connecting-rod ends.

Mr. W. Sмгтн was surprised at the good condition of the indiarubber after having run such a distance, as it did not appear to have suffered at all, and he supposed it must have been well protected from the action of oil or grease; if the india-rubber could be made to stand this application it would no doubt give an ease and softness to the working, and a saving in wear from diminishing the shocks.

Mr. W. Falrbairn believed the application had proved quite successful, and lessened the wear considerably; it was only requisite to take great care to keep oil away from the india-rubber, and in one trial the india-rubber had lasted only a month from neglect of this precaution, but when properly protected from oil its durability was found to be very great. A cap was now fixed over the india-rubber as a more complete protection for this purpose. These axleboxes and connecting rods were working in several locomotives on the Chester and Birkenhead Railway, and they were found to be now as good and perfect as when first put in, though some had run as much as 17,000 miles; they were considered quite satisfactory, and the result of the axleboxes was an improvement in reducing the wear of the wheel flanges. The connecting rods were screwed up at the ends, instead of being cottered as in the usual manner; and this mode of construction he considered an improvement as regarded convenience and security from accident.

Mr. E. A. CowPen thought a small degree of elasticity in the bearing of the axleboxes of carrying wheels, not driving wheels, might be of some advantage by easing the sudden shocks upon the axle guards and wheel flanges, which would then take a soft hold, as it were, instead of a rigid one. He did not see however that the india-rubber lining for the axleboxes could have any effect in making the wheels run better round a curve, as the tendency of an axle was constantly to hang back at the outer end from the line of the radius of the curve, by trying to continue running in a straight line, and thus instead of conforming to a radius it wonld depart further from it. 
Mr. W. Fairbains replied the definite result that had been ascertained was a diminished wear of the wheel flanges where the elastic axleboxes were used.

The Chairman proposed a vote of thanks to Mr. W. A. Fairbairn for his paper, which was passed.

The following Paper, by Mr. John A. Haswell, of Gateshead, was then read :- 
AXLEBOX AND COUPLING ROD.

Plate.41.

Fig.1. Aalebox for

Fig. 3. Leading Whepls.

Fig.4. Axlehox for

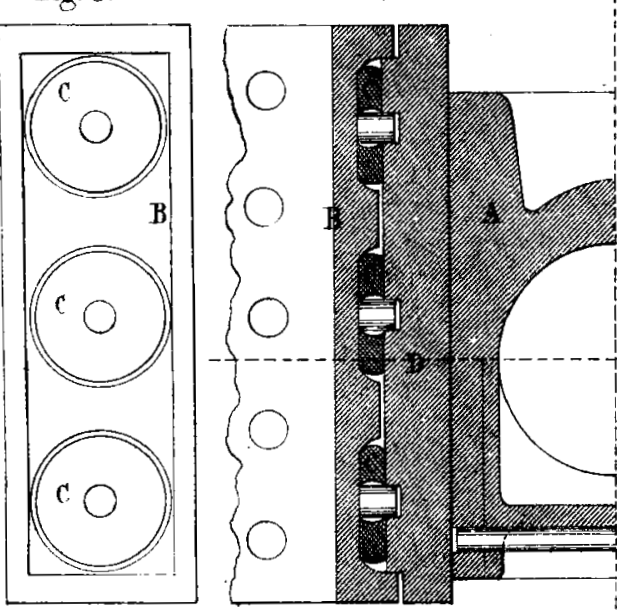

Driving Whels.

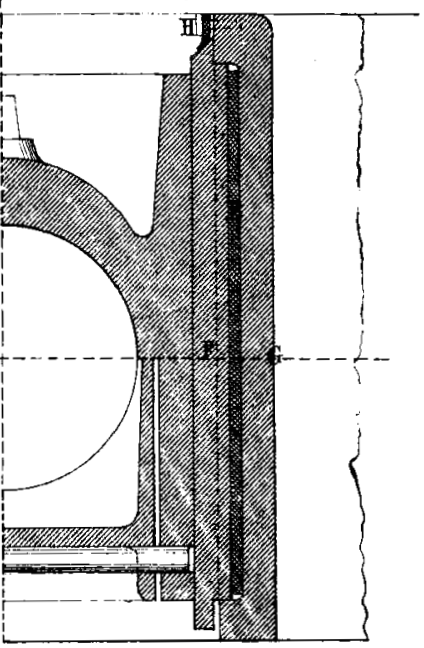

Fig. 2. Plan.

Fig..3. Plan.

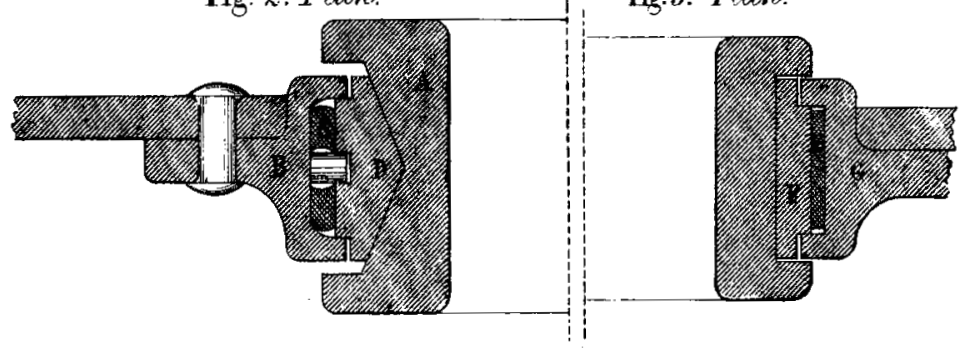

Fig.6. Coupling Rod.

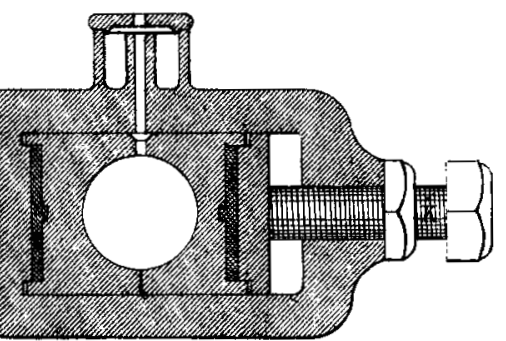

Fig. \%. Plan of Coupling Rod.

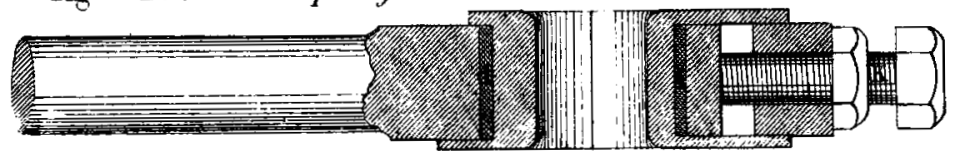

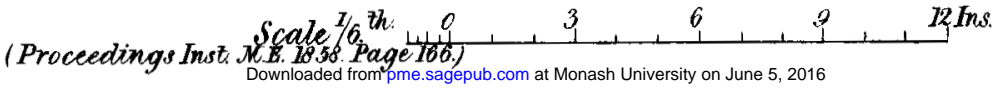

